\title{
Assessment of Clinical and Radiographic Status of Crowned Teeth
}

\author{
Nurul Farahah Bahari ${ }^{1}$, Nur Iffah Izzaty Jamal' ${ }^{2}$ Jacob John ${ }^{3^{*}}$ \\ KEYWORDS \\ crowned teeth; root canal treatment; pulpal pathology; survival outcome
}

\begin{abstract}
This cross sectional study investigated the clinical and radiographic status of crowned teeth with and without root canal treatment. The study used secondary data from records of patients who received crown treatment at the Faculty of Dentistry, University of Malaya before 2015 and walk-in patients attending the primary care clinic between July - December 2016. The inclusion criterion was crown fitted for more than 12 months. Once identified, the patients were assessed for clinical and radiographic status. Data were entered into and analysed using SPSS Version 20 software. A total of 66 crowns [35 root canal treated (RCT) and 31 non-root canal treated (n-RCT)] were identified. Chi-square test was carried out to determine the health of crowned teeth and for its longevity in the oral cavity. There were 43 crowns (46.5\% RCT; $53.5 \% \mathrm{n}-\mathrm{RCT})$ with plaque accumulation, 15 (66.7\% RCT; 33.3\% n-RCT) with gingival swelling/recession, 17 (46.5\% RCT; 53.5\% n-RCT) with widening of the periodontal ligament, 13 (53.8\% RCT; 46.2\% n-RCT) with bone loss and 5 (60\% RCT; 40\% $\mathrm{n}-\mathrm{RCT}$ ) crowns with periapical lesion. There was no statistically significant difference except for poorer alveolar bone condition for crowns that have been in the mouth for $>10$ years. Based on the study, no significant adverse pulpal involvement between crown with RCT and crown without RCT was observed.
\end{abstract}

\section{INTRODUCTION}

Full coverage coronal restoration or crown is an indirect restoration that fits on the remaining structure of the prepared tooth which is needed to protect and restore teeth which have been damaged by wear, trauma, or cycles of caries and repair or to support a missing adjacent tooth. It is also used as permanent restoration following root canal treatment (RCT) as it restores the badly damaged tooth and provides better aesthetics compared to direct restorations like composite. A retrospective study by Nagasiri and Chitmongkolsuk concluded that RCT covered with crowns have a higher long-term survival rate $(81 \pm$ $12 \%$ after 10 years) than RCT without crown coverage (63 $\pm 15 \%$ after 10 years) [1].

\footnotetext{
${ }^{1}$ Klinik Pergigian Pekan, Kuala Kangsar, Jalan Bendahara, 33000Kuala Kangsar, Perak. formerly Faculty of Dentistry, University of Malaya.

${ }^{2}$ Klinik Pergigian Kumia Batu 3, Jalan Gambang, 25150, Kuantan, Pahang. formerly Faculty of Dentistry, University of Malaya.

${ }^{3}$ Department of Restorative Dentistry, Faculty of Dentistry, University of Malaya. Kuala Lumpur, Malaysia.

*Correspondence: drjacob@um.edu.my
}

Rehabilitation of the natural tooth will always be the first choice of treatment for the patient because of its longevity, natural and aesthetic appearance. Van Nieuwenhuysen et al reported a failure rate of $28 \%$ among amalgam restorations as compared to $30 \%$ in resin restorations and $24 \%$ of the crowns while the survival times were 12.8 years, 7.8 years and 14.6 years respectively for amalgam, resin and crown [2]. Elective RCT should be planned for teeth with doubtful pulps scheduled for any form of crown procedures as well as teeth that cannot be restored without using pulp chamber and root canal for support and/or retention [3].

Badly damaged crowns with RCT can utilize the root canal space for retention and support. Studies have shown that ceramic coverages placed on nonvital teeth failed in $9.7 \%$ of cases and $6.6 \%$ on vital teeth [4]. In addition, endodontically treated teeth need crown as permanent restoration especially in the posterior region where it is involved primarily for mastication [5]. Nagasiri and Chitmongkolsuk in 
their study showed that of the 220 uncrowned endodontically treated molars, 101 teeth were found to have some changes over an observation period of 6 months to 10.2 years and their survival rates at 1,2 , and 5 years were $96 \%, 88 \%$, and $36 \%$, respectively [1]. Another study reported that endodontically treated anterior tooth restored with crown with a cast post and core foundation and a crown had a higher risk of failure than in posterior tooth [6].

However, vital teeth can also lose their vitality after being restored with full coverage crown due to several reasons including the crown preparation procedure itself. Numerous studies have shown that procedural factors involved in crown fabrication including cutting enamel-dentine, illfitting provisional restoration, toxicity of material, micro leakage of cements and occlusion can cause irreversible pulp damage [7]. High speed bur stripping of hard tissue poses the threat of pulpal overheating by change in microcirculation, vascular stasis, thrombosis, reduced blood flow and internal bleeding [8]. It also opens the dentinal tubules to communicate directly to the pulp. This increases the permeability of pulp towards chemical, physical, and microbial irritants. Another study reported that tooth reduction procedures could be performed without significant damage to the pulp when air alone was used as a coolant [9]. Cheung et al reported that three of 73 previously vital tooth restored with single crown were deemed to have failed because they became periapically involved or had been root canal treated after a mean observation period of 34 months [10]. Full coverage restoration on vital teeth protects pulp by preventing tooth fracture but, dental literature also reports $3 \%$ to $25 \%$ pulpal necrosis rate as a result of preparation on complete coverage restoration $[11,12]$.

Dental practitioners wish for success in their restorative work to do the best for their patients, but increasingly the avoidance of failure, is felt to be necessary to steer clear of litigation. With the exception of some of the above studies, subjective evidence has been the primary basis for deciding whether a full coverage coronal restoration or crown should or should not follow routine RCT. It is hypothesized that unless patients complain, the crowned teeth with or without RCT are always successful. This cross sectional study sought to investigate the clinical and radiographic status of crowned teeth, comparing between those with and without RCT and duration of placement of the crown.

\section{MATERIALS AND METHODS}

This study was conducted in between February and September 2016 at the University of Malaya Faculty of Dentistry (UMFoD) dental poly clinic. The study was approved by the Medical Ethics Committee, Faculty of Dentistry of University of Malaya. The inclusion criteria for selection of subjects included those who had one or more full coverage coronal crown placed on or before $31^{\text {st }}$ December 2014.

Two sets of respondents were recruited for the study. The dental records of former patients, who remained active in the practice since 2008, were examined. The records were reviewed for clinical outcomes with regard to teeth with existing full coverage coronal crown history, clinical examination, special tests, and radiological examination. Those patients who fulfilled the study criteria were contacted by telephone and given appointment for a dental checkup which included the clinical and radiographic reevaluation of the crowned tooth. The other set of respondents were walk in patients to the outpatient clinic of the UMFoD.

All participants signed an informed consent before undergoing the examination. Examination was carried out by two calibrated examiners, who conducted a relevant history taking as well as clinical and radiological examination for signs and symptoms of caries or pulpal of the crowned tooth. Patients were asked about any discomfort or pain on the crowned tooth. The clinical examination was carried out by inspection and palpation to investigate any sign and symptom of dental caries and pulpal inflammation spontaneous pain, presence of swelling or sinus discharge, plaque accumulation and gingival health. Periapical radiograph of the crowned tooth was taken to assess periapical condition which shows sign of pulpal inflammation, bone status of crowned tooth, margins of crown, any radiolucency beneath crown, and any presence of periapical radiolucency, discontinuation of lamina dura, resorption, or any change in periodontal ligament space. After the examination, all respondents were categorized into groups namely those having crown with and without root canal treated (RCT) and according to the number of years the crown has been in the mouth.

The collected data were compiled and subjected to descriptive analysis and categorical analysis using Chi-square test with SPSS Version 20 software. The 
relationship between the teeth crowned with and without RCT and the duration of placement were

\section{RESULTS}

A total of 66 full coverage crowns were identified for this study. Majority of the respondents were Chinese (62.1\%), female (59.1\%) and aged between 23 to 74 years (Table 1 ).

Table 1. Sociodemographic representation of the study population.

\begin{tabular}{llcc}
\hline & & $\mathbf{n}$ & $\mathbf{\%}$ \\
\hline \multirow{2}{*}{ Race } & Malay & 17 & 25.8 \\
& Indian & 8 & 12.1 \\
& Chinese & 41 & 62.1 \\
\hline \multirow{2}{*}{ Gender } & Male & 27 & 40.9 \\
& Female & 39 & 59.1 \\
\hline \multirow{2}{*}{ Age } & 49 and below & 30 & 45.5 \\
range & 50 and above & 36 & 54.5 \\
\hline
\end{tabular}

Table 2 describes the location and characteristics of the crowns examined for this study. Majority of the crowns were located in the anterior (71.6\%) and upper (74.6\%) segment of the jaw. $53.7 \%$ of the crowns were placed after RCT. Most of the crowns were constructed and cemented for more than 5 years.

The crowns consisted of 57 metal ceramic, 5 full metal and 5 full ceramic crowns. Table 3 and 4 compares the clinical and radiographic condition of crowns with and without RCT and its duration in the oral cavity. Comparing those with and without $\mathrm{RCT}$, there was no statistically significant examined using the chi-square test.

difference between the two groups except for bone level.

Table 2. Location and characteristics of the crowns.

\begin{tabular}{llcc}
\hline \multirow{2}{*}{ Region } & & $\mathbf{n}$ & $\mathbf{\%}$ \\
\hline \multirow{2}{*}{ Jaw } & Anterior & 48 & 71.6 \\
& Posterior & 18 & 28.4 \\
\hline \multirow{2}{*}{ RCT } & Upper & 50 & 74.6 \\
& lower & 16 & 25.4 \\
\hline \multirow{4}{*}{ Duration } & Yes & 35 & 53.7 \\
& No & 31 & 46.3 \\
\hline \multirow{4}{*}{ Type } & $1-4$ yr & 15 & 22.4 \\
& 5-9yr & 30 & 46.3 \\
& $10-19 y r$ & 11 & 16.4 \\
& $>20$ yr & 10 & 14.9 \\
\hline
\end{tabular}

There was more plaque accumulation (74 vs $57 \%$ ) around crowns without RCT. Gingival inflammation ( 29 vs $16 \%$ ) and widening of periodontal ligament ( 29 vs $22 \%$ ) was higher among teeth with RCT. The bone level around teeth with restorations more than 10 years have statistically significant recession (79 vs $65 \%$ ) than those restored for less than 10 years $(p<0.05)$. However, crowns restored less than 10 years showed more accumulation of plaque, poorer gingival health, more widening of the PDL and PA lesion.

Table 3. Clinical and radiographic observation of the crowns with $(\mathrm{N}=35)$ and without $\mathrm{RCT}(\mathrm{N}=31)$

\begin{tabular}{|c|c|c|c|c|c|}
\hline & & With RCT [N (\%)] & Without RCT [N (\%)] & $x^{2}(d f)^{a}$ & p-value \\
\hline \multirow{2}{*}{$\begin{array}{l}\text { Plaque } \\
\text { accumulation }\end{array}$} & Yes & $20(57.1)$ & $23(74.2)$ & $2.11(1)$ & 0.147 \\
\hline & No & 15 (42.9) & $8(25.8)$ & & \\
\hline \multirow[t]{2}{*}{ Gingival health } & Normal & $25(71.4)$ & $26(83.9)$ & $1.45(1)$ & 0.290 \\
\hline & Abnormal & $10(28.6)$ & $5(16.1)$ & & \\
\hline \multirow[t]{2}{*}{ PDL widening } & Yes & $10(28.6)$ & $7(22.6)$ & $0.31(1)$ & 0.579 \\
\hline & No & $25(71.4)$ & $24(77.4)$ & & \\
\hline \multirow[t]{2}{*}{ Bone level } & Normal & $28(80.0)$ & $25(80.6)$ & $0.004(1)$ & 0.948 \\
\hline & Abnormal & $7(20.0)$ & $6(19.4)$ & & \\
\hline \multirow{2}{*}{$\begin{array}{l}\text { Periapical } \\
\text { lesion }\end{array}$} & Yes & $3(8.6)$ & $2(6.5)$ & $0.11(1)$ & 0.745 \\
\hline & No & $32(91.4)$ & $29(93.5)$ & & \\
\hline
\end{tabular}

${ }^{a}$ chi square test for independence

\section{DISCUSSION}

This is a cross sectional study that compared the clinical and radiographic condition of teeth after at least 1-year placement of full coverage crown with and without RCT. Some of the commonest causes reported on failure of crowned teeth include caries $[13,14]$, decementation [13], pulpal and endodontic problems [15] and mechanical fractures [15]. Based on a recent systematic review [16], survival rates against fracture of posterior endodontically treated teeth (ETT) restored with either full-coverage crowns or direct resin composite restorations were not significantly different in the teeth with minimal to moderate loss of tooth structure. 
Table 4. Clinical and radiographic condition in comparison with duration of placement of the crowns

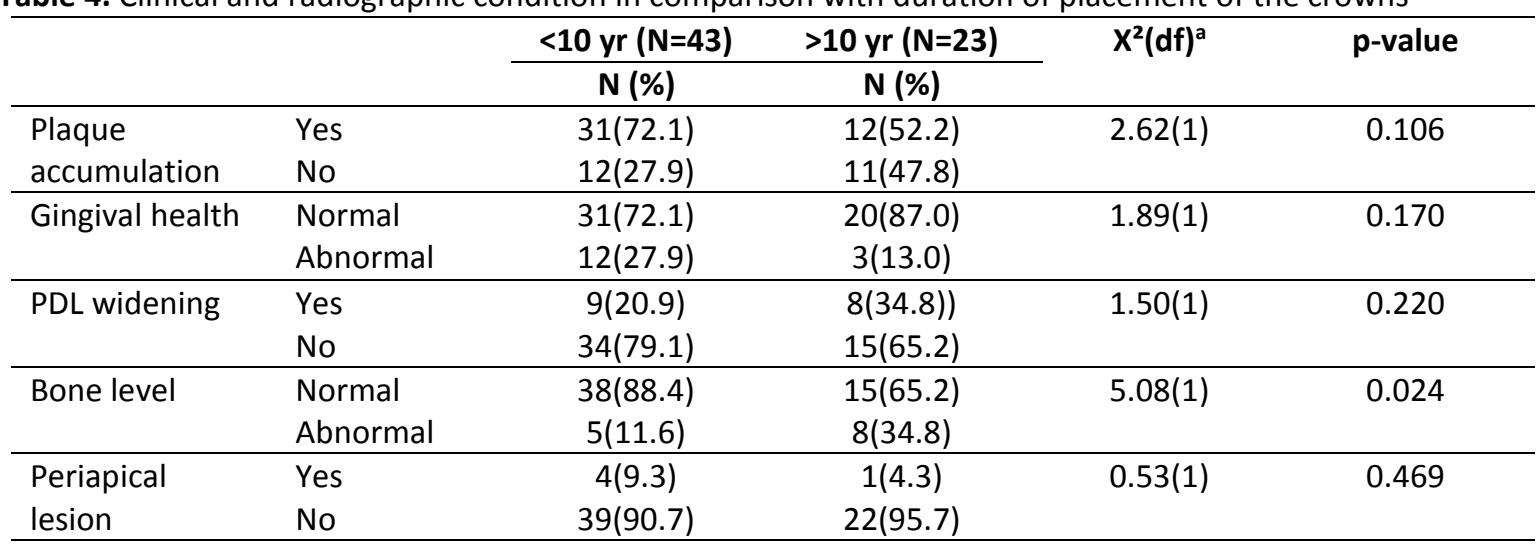

${ }^{\mathrm{a}}$ chi square test for independence

Overall survival rates against fracture of these crowns ranged from $94 \%$ to $100 \%$, while those of resin composite restorations ranged from $91.9 \%$ to $100 \%$. It has been mentioned that pulp testing is not a good indicator of the pulp condition [17]. It is used to provide information regarding presence of viable pulp tissue. In our study, plaque accumulation and condition of surrounding gingiva were used to determine the clinical health of the crowned tooth. While for radiograph, the criteria that were examined were status of periodontal ligament space, presence of periapical lesion, bone level.

Periodontal health can be defined as a state free from inflammatory periodontal disease that allows an individual to function normally and not suffer any consequences (mental or physical) as a result of past disease [18]. Gingival inflammation in response to bacterial plaque accumulation (microbial biofilms) is considered the key risk factor for the onset of periodontitis [19].

Clinical gingival health on an intact periodontium is characterized by the absence of bleeding on probing, erythema and edema, patient symptoms, and attachment and bone loss. Physiological bone levels range from 1.0 to $3.0 \mathrm{~mm}$ apical to the cemento-enamel junction [20].

Generally, there is no statistically significant difference between crown with RCT and crown without RCT on all the variables. When comparing the result with other published studies, there was a study that showed $3 \%$ to $25 \%$ pulpal necrosis rate observed in teeth with full coverage crown over an 18 month to 25-year period [21]. In addition, $20 \%$ to $50 \%$ re-treated cases by endodontist are performed on crowned teeth. One of the factors that might contribute to the finding is the procedure during crown preparation. High speed stripping of hard tissue poses the threat of pulpal overheating, with disturbance of microcirculation, vascular stasis, thrombosis, reduced blood flow and internal bleeding [8]. Besides, it also opens a multitude of dentinal tubules that communicate directly with the pulp. The deeper the dentine is cut, the more permeable it is and the more vulnerable the pulp becomes to chemical, physical and microbial irritants [8]. The microbial threat presented by the oral flora is by far the most serious, and is capable of heralding intense inflammatory changes, with micro-abscess formation and progressive pulpal necrosis [22,23]. Apart from the procedure of crown preparation, some studies showed that factor that might cause secondary pulpal involvement of crowned tooth are frictional heat, desiccation, pressure applied during tooth reduction, chemical injury, ill-fitting provisional restorations, bacterial infection, cementation, and occlusion [9]. One retrospective study [24] found that teeth that received crown 4 months after RCT were almost 3 times more likely to get extracted compared with teeth that received crown within 4 months of RCT.

Bergenholtz and Nyman's much quoted study [25] showed that $9 \%$ of crowned teeth, compared to only $2 \%$ of uncrowned controls lost vitality during long-term review. Even higher levels of pulp death were recorded by Felton et al [26] where $13.3 \%$ of teeth restored with full coverage crowns, compared with $0.5 \%$ of unrestored controls lost vitality during the 3-30 year review period. But it was not possible to derive from those reports how many teeth had suffered further pulpal insult, such as recurrent caries, which may have artificially inflated the adverse effects reported. A more realistic estimation may be in the order of $4-8 \%$ in the 10 years following active treatment $[27,28,29]$. 
This estimation assume that efforts were made to identify and manage all obvious pulpal pathosis before crowns were made; an assumption that cannot always be taken for granted in practice and which increases the likely incidence of unexpected endodontic problems that need attention at a later date [8].

In our study, except for the bone lever $(P=.024)$, we found statistically insignificant difference between teeth crowned for less and more than 10 years. In a study by De Backer et al [30] on 1037 complete crowns, the estimated survival rates at year 18 were $74.9 \%$ for the vital group and $79.4 \%$ for the RCT group $(P=.602)$. Bone support in the oral cavity is influenced by many factors like patient's oral hygiene, underlying medical problem, iatrogenic factors and age of patient. In this study, majority of the respondents were aged $>50$ years. This might influence our findings because absorption of calcium and production of vitamin $D$ declines with age; with impaired absorption of calcium and low production of vitamin $D$, older patient has high risk to bone loss and has low bone fracture resistance [31].

Based on literature, periapical healing should take place within 2-5 years of completion of RCT procedure [32] which is indicated by the reduction in size of the periapical lesion. Another study noted that the reason for failure in endodontic treatment is due to failure to eliminate all bacteria from root canal space [33]. Therefore, it is important to shape and clean the root canal spaces before permanent seal to ensure periapical healing. Eliminations of bacteria in canal space can be done chemically and mechanically during cleaning and shaping stage and by the use of intracanal medicament. During the shaping stage, endodontic instruments like files are used to remove the bacteria and debris on the dentinal walls and the canals are irrigated with irrigant like sodium hypochlorite which is an antimicrobial in properties to flush out all debris and microorganisms [25].

There are some limitations in our study which may have had an effect on the outcome. Firstly, the study period was conducted for a short period due to limitation of time. We were not able to include more study samples because some of the patients we identified through our records were not able to attend the clinic during the stipulated time. Due to limited number of samples, we cannot conclusively verify our findings. We need further study with larger sample size to confirm our findings.

\section{CONCLUSIONS}

Within the limitation of this study, we found crowns with RCT and without RCT did no show much clinical and/or radiographic pathology. There was no statistically significant difference in the long-term survival of the crowned teeth. The most significant factor noticed was reduced alveolar bone level among teeth crowned for more than 10 years. However, alveolar bone loss can also be due to ageing, poor oral hygiene, underlying medical problem or generalized periodontal problem. All teeth scheduled to be crowned, whether they are presumed to have healthy pulps or previously root-treated should be thoroughly assessed at the planning stage.

\section{DECLARATION OF INTEREST}

The authors report no conflicts of interest. The authors alone are responsible with the content of this article.

\section{INFORMED CONSENT}

The study procedures have been approved by the Medical Ethics Committee, Faculty of Dentistry, University Malaya. (No. DF RD1605/0018(U))

\section{REFERENCES}

1. Nagasiri R, Chitmongkolsuk S. Long-term survival of endodontically treated molars without crown coverage: a retrospective cohort study. J Prosthe Dent, 2005;93,164-170.

2. Van Nieuwenhuysen JP, D'Hoore W, Carvalho J, Qvist V. Long-term evaluation of extensive restorations in permanent teeth. J Dent, 2003;31,395-405.

3. Ahmed A, Mohamed $H$. Elective root canal treatment: A review and clinical update. ENDO, 2014:8,139-144.

4. Van Dijken JW, Hasselrot L, Örmin A, Olofsson AL. Restorations with extensive dentin/enamel-bonded ceramic coverage. A 5-year follow-up. Eur J Oral Sci, 2001;109,222-229.

5. Schwartz RS, Robbins JW. Post placement and restoration of endodontically treated teeth: A 
literature review. Journal of Endodontics, 2004;30: 289-301.

6. Aquilino SA, Caplan DJ. Relationship between crown placement and the survival of endodontically treated teeth. J Prosthe Dent, 2002;87,256-263.

7. Torabinejad M, Goodacre CJ. Endodontic or dental implant therapy: the factors affecting treatment planning. J Am Dent Assoc, 2006;137,973-977.

8. Whitworth J, Walls A, Wassell R. Crowns and extra-coronal restorations: endodontic considerations: the pulp, the root-treated tooth and the crown. Br Dent J, 2002;192,315-327.

9. Lockard MW. A retrospective study of pulpal response in vital adult teeth prepared for complete coverage restorations at ultrahigh speed using only air coolant. J Prosthe Dent, 2002;88,473-478.

10. Cheung G, Lai S, Ng R. Fate of vital pulps beneath a metal-ceramic crown or a bridge retainer. Int Endod J, 2005;38,521-530.

11. McCabe $\mathrm{P}$, Dummer PMH. Pulp canal obliteration: an endodontic diagnosis and treatment challenge. Int Endod J, 2012;45,177-197.

12. Viţalariu A, Căruntu ID, Bolintineanu S. Morphological changes in dental pulp after the teeth preparation procedure. Rom J Morphol Embryo, 2005;46,131-136.

13. Briggs $P$, Ray-Chaudhuri A, Shah K. Avoiding and managing the failure of conventional crowns and bridges. Dent Update, 2012;39,78-84.

14. Holm C, Tidehag $P$, Tillberg A, Molin M. Longevity and quality of FPDS: A retrospective study of restorations 30, 20, and 10 years after insertion. Int J Prosthodont, 2003;16,283-289.

15. Tan K, Pjetursson BE, Lang NP, Chan ES. A systematic review of the survival and complication rates of fixed partial dentures (FPDs) after an observation period of at least 5 years. Clin Oral Implants Res, 2004; 15,654-666.

16. Suksaphar W, Banomyong D, Jirathanyanatt T, Ngoenwiwatkul Y. Survival rates against fracture of endodontically treated posterior teeth restored with full-coverage crowns or resin composite restorations: A systematic review. Restor Dent Endod, 2017;42,157-167.

17. Jafarzadeh $\mathrm{H}$, Abbott P. Review of pulp sensibility tests. Part I: General information and thermal tests. Int Endod J, 2010; 43,738-762.

18. Lang NP, Bartold PM. Periodontal health. J Periodontol, 2018;89,S9-S16.

19. Murakami S, Mealey BL, Mariotti A, Chapple ILC. Dental plaque-induced gingival conditions. J Clin Periodontol, 2018;45,S17-S27.

20. Chapple IL, Mealey BL, Van Dyke TE, Bartold PM, Dommisch H, Eickholz P, Geisinger ML, Genco RJ, Glogauer $\quad M$, Goldstein $\quad M$, Griffin TJ, Holmstrup $\quad P$, Johnson GK, Kapila $Y$, Lang NP, Meyle J, Murakami S, Plemons J, Romito GA, Shapira L, Tatakis DN, Teughels W, Trombelli L, Walter C, Wimmer G, Xenoudi P, Yoshie H.Periodontal health and gingival diseases and conditions on an intact and a reduced periodontium: Consensus report of workgroup 1 of the 2017 World Workshop on the Classification of Periodontal and Peri-Implant Diseases and Conditions. J Periodontol, 2018;89,S74-S84.

21. Kirakozova A., Caplan D.J. Predictors of root canal treatment in teeth with full coverage restorations. J Endod,(2006);32,727-730.

22. Cox CF, Sübay RK, Suzuki S, Suzuki SH, Ostro E. Biocompatibility of various dental materials: pulp healing with a surface seal. Int J Periodontics Restorative Dent, 1996; 16,240-51.

23. Bergenholtz G. Latrogenic injury to the pulp in dental procedures: Aspects of pathogenesis, management and preventive measures. Int Dent J, 1991; 41,99-110.

24. Pratt I, Aminoshariae A, Montagnese TA, Williams KA, Khalighinejad N, Mickel A. . Eight-year retrospective study of the critical time lapse between root canal completion and crown placement: Its influence on the survival of endodontically treated teeth. J Endod, 2016;42,1598-1603.

25. Bergenholtz G, Nyman S. Endodontic complications following periodontal and prosthetic treatment of patients with advanced periodontal disease. J Periodontol, 1984;55,63-68.

26. Felton D. Long term effects of crown preparation on pulp vitality. J Dent Res, 1989;68,1009. 
27. Valderhaug J, Jokstad A, Ambjørnsen E, Norheim P. Assessment of the periapical and clinical status of crowned teeth over 25 years. J Dent, 1997;25,97-105.

28. Gonzalez G, Wier D, Helm F, Marshall S, Walker L, Stoffer W. Incidence of endodontic treatment in teeth with full coverage restorations. J Dent Res, 1991;70,446.

29. Reichen-Graden S, Lang N. Periodontal and pulpal conditions of abutment teeth. Status after four to eight years following the incorporation of fixed reconstructions. Schweiz Monatsschr Zahnmed, 1988;99,1381-1385.

30. De Backer H, Van Maele G, Decock V, Van den Berghe L. Long-term survival of complete crowns, fixed dental prostheses, and cantilever fixed dental prostheses with posts and cores on root canal-treated teeth. Int J Prosthodon, 2007;20,229-234.

31. Dawson-Hughes B, Harris SS, Krall EA, Dallal GE. Effect of calcium and vitamin D supplementation on bone density in men and women 65 years of age or older. N Engl J Med, 1997;337,670-676.

32. Trautmann G, Gutmann JL, Nunn ME, Witherspoon DE, Shulman JD. Restoring teeth that are endodontically treated through existing crowns. Part I: Survey of pulpal status on access. Quintessence Int, 2000;31,713-718.

33. Stuart $\mathrm{CH}$, Schwartz SA, Beeson TJ, Owatz CB. Enterococcus faecalis: Its role in root canal treatment failure and current concepts in retreatment. J Endod 2006;32,93-98.

License Information: This work is licensed under a Creative Commons Attribution 